\title{
Impact of Initial Condition on Prediction of Bay of Bengal Cyclone 'Viyaru' - A Case Study
}

\author{
K. S. Singh \\ Centre for Oceans, Rivers, \\ Atmosphere and Land \\ Sciences (CORAL), \\ Indian Institute of Technology \\ Kharagpur, \\ Kharagpur -721302, \\ West Bengal, India
}

\author{
M. Mandal \\ Centre for Oceans, Rivers, \\ Atmosphere and Land \\ Sciences (CORAL), \\ Indian Institute of Technology \\ Kharagpur, \\ Kharagpur -721302, \\ West Bengal, India
}

\begin{abstract}
Accurate prediction of track and intensity of land-falling tropical cyclones is of the great importance in weather prediction in making an effective tropical cyclone warning. This study examines the impact of initial condition on real time prediction of Bay of Bengal cyclone Viyaru. For this purpose, the customized version of Advanced Research core of Weather Research and Forecasting (ARW-WRF) model with two-way interactive double nested model at $27 \mathrm{~km}$ and 9 $\mathrm{km}$ resolutions is used to predict the storm. The model initial conditions are derived from the FNL analysis and Global Forecasting System (GFS) analysis and the lateral boundary condition is provided every 3 hourly from GFS forecast. The model predicted track and intensity of the storm are compared with the India Meteorological Department (IMD) best-fit track. Results indicate that the track of the storm is reasonably well predicted by the model with both FNL and GFS initial condition. The track of the storm is better predicted by the model with FNL initial condition. It is found that in reference to the track predicted errors with GFS initial condition, the use of FNL initial analysis as condition resulted in $41 \%, 8 \%$, $5 \%$ and $19 \%$ improvement respectively in $24 \mathrm{~h}, 48 \mathrm{~h}, 72 \mathrm{~h}$, and 96h forecast. This is due to less initial positional error in FNL analysis. The landfall time and location of the storm is also better predicted by the model with FNL initial condition. The trend of intensification and dissipation of the storm is also better predicted with FNL as the initial condition. The intensity of the storm in term of central sea level pressure (CSLP) and maximum surface wind (MSW) is over-predicted by the model with both initial conditions. The 24 hours accumulated precipitation around the landfall time is also better predicted by the model with FNL initial condition.
\end{abstract}

\section{General Terms}

Prediction, WRF model, tropical cyclone

\section{Keywords}

Viyaru, Bay of Bengal, pressure, wind, precipitation.

\section{INTRODUCTION}

Tropical cyclone (TC) is one of the devastating natural disasters in the coastal region. The destruction is mainly due to the strong wind, heavy rainfall and associated storm surges, when storm crossed the coast [1]. The Bay of Bengal is a potentially active region for formation of the TC and accounts for about $6 \%$ of the global annual total number of tropical storms [2]. The genesis of TCs over BOB is highly seasonal, with primary maximum in the post-monsoon season (October to December) and secondary maximum during the premonsoon season (April and May). The TCs over BOB are moderate in size and intensity, but the death toll associated with these storms is highest in the world. This is due to the geographical structure of the Bay of Bengal, densely populated coastal region, shallow bathymetry, nearly funnels shape of the coastline, poor socio-economic conditions and presence of many rivers. Beside human causality TCs cause huge damage to property. So, it is very important to predict the track (including landfall time and location) and intensity of these storms as accurately as possible.

There is significant improvement in numerical prediction of TC in last three decades. In last two decades the focus is on high resolution mesoscale prediction of TCs. Though prediction of track is improved steadily [3, 4], the improvement in prediction of intensity is limited particularly, prediction of rapid intensification and dissipation. The improvement in track prediction is mainly due to better representation of the large-scale steering flows that are gradually better resolved by global numerical weather prediction (NWP) models. Whereas TC intensity is influenced by inner core dynamics, smaller scale physical processes (such as planetary boundary layer (PBL) cumulus convection, radiation and microphysics) and accurate storm initial structure in numerical models. That is not well resolved or parameterized in global and even regional models $[5,6]$. The necessity to better resolve the inner core has led to the application of high resolution mesoscale model [e.g., 7, 8, 9 and 10]. It is also recognized that the accurate prediction of tropical cyclones structure and intensity changes are closely related to the storm inner core structure and their evolution $[11,12$ and 13].

Presently, models are used with the global analysis and forecasted data sets as initial and boundary conditions to achieve greater accuracy of tropical cyclones track and intensity prediction, especially with 3-4 days to have lead time forecast. The initial conditions derived from global analysis to mesoscale models are insufficient in representing the position of the vortex and the initial structure of the storm. Even a small error in initial condition may contribute large error in subsequent forecast [14]. Several numerical studies have demonstrated that the inclusion of satellite and Doppler 
Weather Radar (DWR) observations, near and around the centre of the storm using data assimilation method, can substantially improve the initial condition of the TCs and hence the prediction of track, intensity and structure of the storm $[15,16,17,18,19,20,21,22,23]$. So, it is also important to study the impact of initial condition. It is expected that better initial conditions derived from GFS and FNL analysis produce better forecast.

In this study, an Advanced Research core of Weather research and forecasting (ARW-WRF) model is used to predict the Bay of Bengal cyclone 'Viyaru' which crossed Bangladesh coast on 16 May 2013. A brief description of the cyclonic storm is presented in section 2 . The description and configuration of WRF model used in the study is provided in section 3 . The numerical experiments and data used are discussed in section 4. The results obtained from the model predictions and related discussions are presented in section 5 followed by conclusion in section 6 .

\section{DESCRIPTION OF THE CYCLONIC STORM VIYARU}

A low pressure area formed over the southeast Bay of Bengal on 10 May 2013 about 09:00 UTC near $\left(5.0^{\circ} \mathrm{N}, 92.0^{\circ} \mathrm{E}\right)$. It moved northwestward and intensified into a deep depression by 12:00 UTC of 10 May. Moving in northwestward direction, the system further intensified into a cyclonic storm named "Viyaru" around 03:00 UTC of 11 May 2013. Under the influence of anti-cyclonic circulation the storm lying to the east and changed its direction of movement initially from northwesterly to northerly and then north-northeasterly on 13 May and 14 May 2013 respectively. The cyclonic storm Viyaru moving faster with a speed of 40-45 kts on 16 May 2013 and made landfall around 08:00 UTC. Such speed in any of cyclonic storm since before the landfall is quite absent. The cyclonic storm moved very fast with a speed of $40-45 \mathrm{~km} / \mathrm{h}$ on 16 May of landfall. After the landfall, the storm continued to move in a north-northeastward direction and gradually weakened into a deep depression over Mizoram by 12:00 UTC of 16 May. It further dissipated into a depression over Manipur around at 18:00 UTC on 16 May 2013. It is regarded as one of the cyclones with the longest track over the Bay of Bengal. The track of the storm 'Viyaru' is given in Fig 1.

\section{MODEL DESCRIPTION AND CONFIGURATION}

The Advanced Research core of Weather Research and Forecasting (ARW-WRF) model is developed at the National Center for Atmospheric Research (NCAR) in collaboration with a number of agencies viz., the National Oceanic and Atmospheric Administration (NOAA), the National Center for Environmental Prediction (NCEP) and various universities. It is based on an Eulerian solver for the fully compressible nonhydrostatic equations with complete Coriolis and curvature terms. The grid staggering is the Arakawa C-grid.

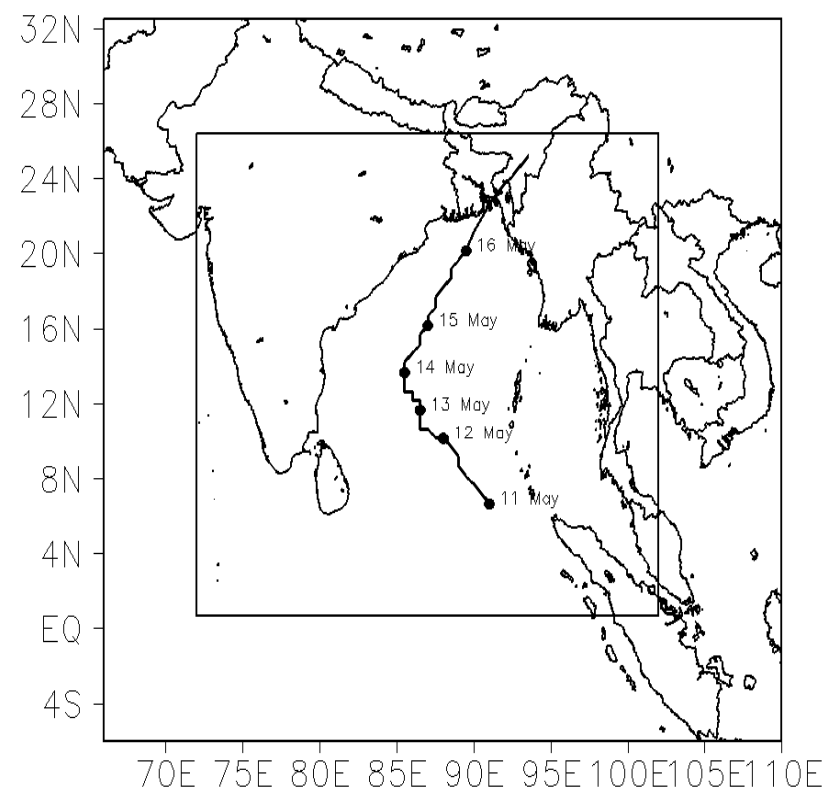

Fig 1: Model domain with IMD best-fit track of cyclone Viyaru during 11-17 May 2013.

Table 1. Overview of WRF model configuration

\begin{tabular}{|c|c|}
\hline Dynamics & Non-hydrostatic \\
\hline Model domain & $\begin{array}{c}6.0^{\circ} \mathrm{S}-32.5^{\circ} \mathrm{N}, 66^{\circ} \mathrm{E}-110^{\circ} \mathrm{E}(\mathrm{D} 1) \\
0.5^{\circ} \mathrm{N}-26.5^{\circ} \mathrm{N}, 72^{\circ} \mathrm{E}-102^{\circ} \mathrm{E} \\
\text { (D2) }\end{array}$ \\
\hline Horizontal grid length & $27 \mathrm{~km}$ and $9 \mathrm{~km}$ \\
\hline No. of vertical levels & 35 \\
\hline Vertical coordinates & $\begin{array}{l}\text { Terrain-following hydrostatic } \\
\text { pressure vertical co-ordinates }\end{array}$ \\
\hline Time integration scheme & Runga-Kutta $3^{\text {rd }}$ order \\
\hline Map projection & Mercator \\
\hline Horizontal grid system & Arakawa C-grid \\
\hline $\begin{array}{l}\text { Spatial differencing } \\
\text { scheme }\end{array}$ & 6th order center differencing \\
\hline Long wave Radiation & RRTM scheme \\
\hline Short wave radiation & Dudhia scheme \\
\hline Land surface model & Unified Noah LSM \\
\hline PBL scheme & YSU \\
\hline Microphysics & Lin \\
\hline $\begin{array}{c}\text { Cumulus } \\
\text { parameterization }\end{array}$ & $\begin{array}{l}\text { Old Simplied Arakawa- } \\
\text { Schubert (SAS4) }\end{array}$ \\
\hline
\end{tabular}

The terrain-following hybrid sigma-pressure is used as vertical coordinate with the top of the model being a constant 
pressure surface. The solver uses the $2 \mathrm{nd}$ and $3 \mathrm{rd}$ order Runge-Kutta time integration scheme, 2nd to 6th order advection in both horizontal and vertical directions and timesplitting technique for using smaller time steps for acoustic and gravity-wave modes. WRF model incorporates various physical processes including cumulus parameterization, planetary boundary layer, microphysics, surface layer, land surface, shortwave radiation and long-wave radiation, with several options available for each process.

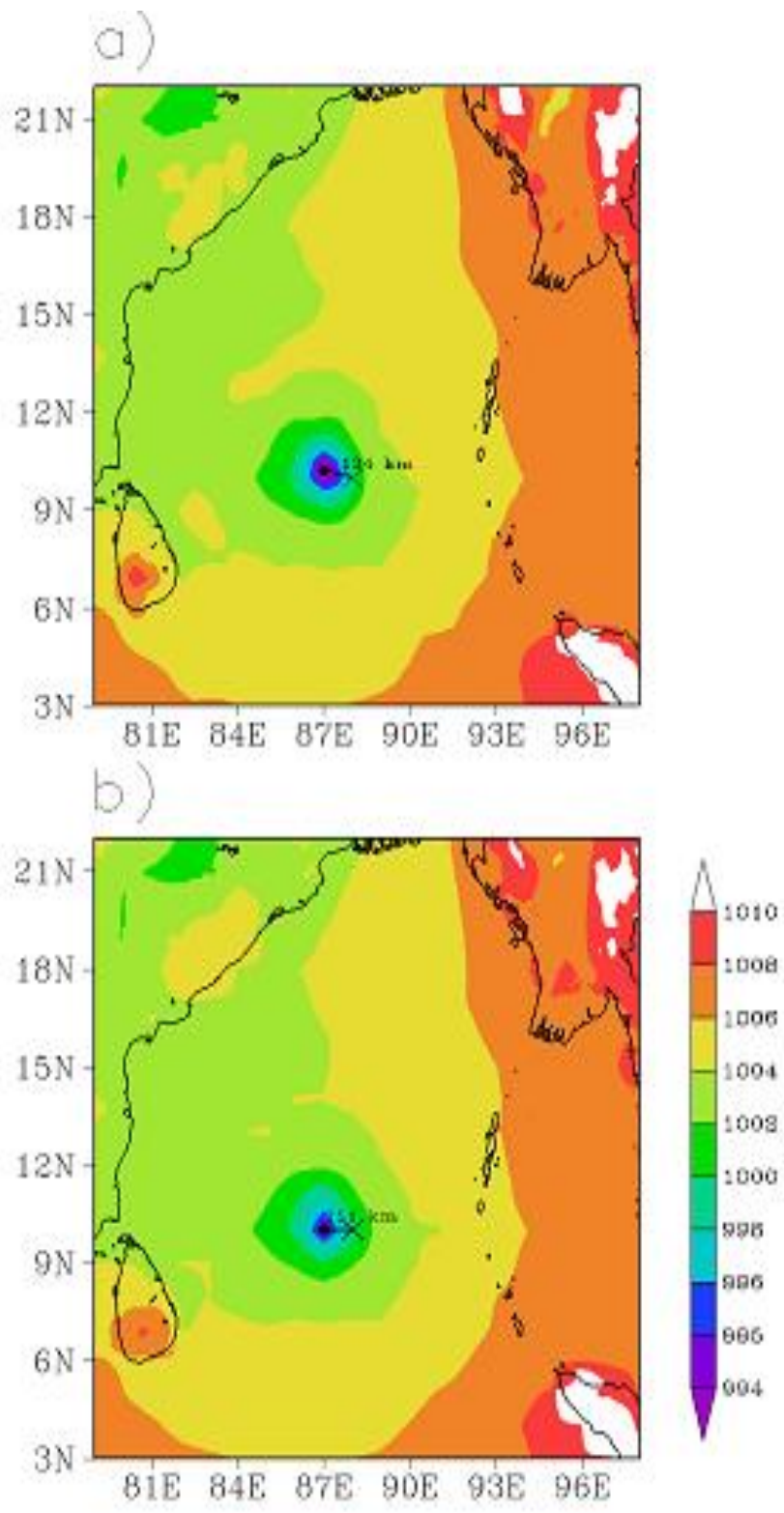

The mesoscale model WRF-ARW described above is used with a two-way interactive double nested domain at $27 \mathrm{~km}$ and $9 \mathrm{~km}$ horizontal resolution. The model domains are shown in Fig 1. There are 35 vertical sigma levels with higher resolution within the boundary layer (BL) while the model top is set to $10 \mathrm{hPa}$. The overview of the model used in the study is given in Table 1. The model physics considered in this study are the old Simplied Arakawa-Schubert (SAS) cumulus scheme [24]; Yonsei University (YSU) PBL scheme [25]; Lin microphysics scheme [26]; the Rapid Radiative Transfer Model for longwave radiation [27] and Dudhia's scheme for shortwave radiation [28].

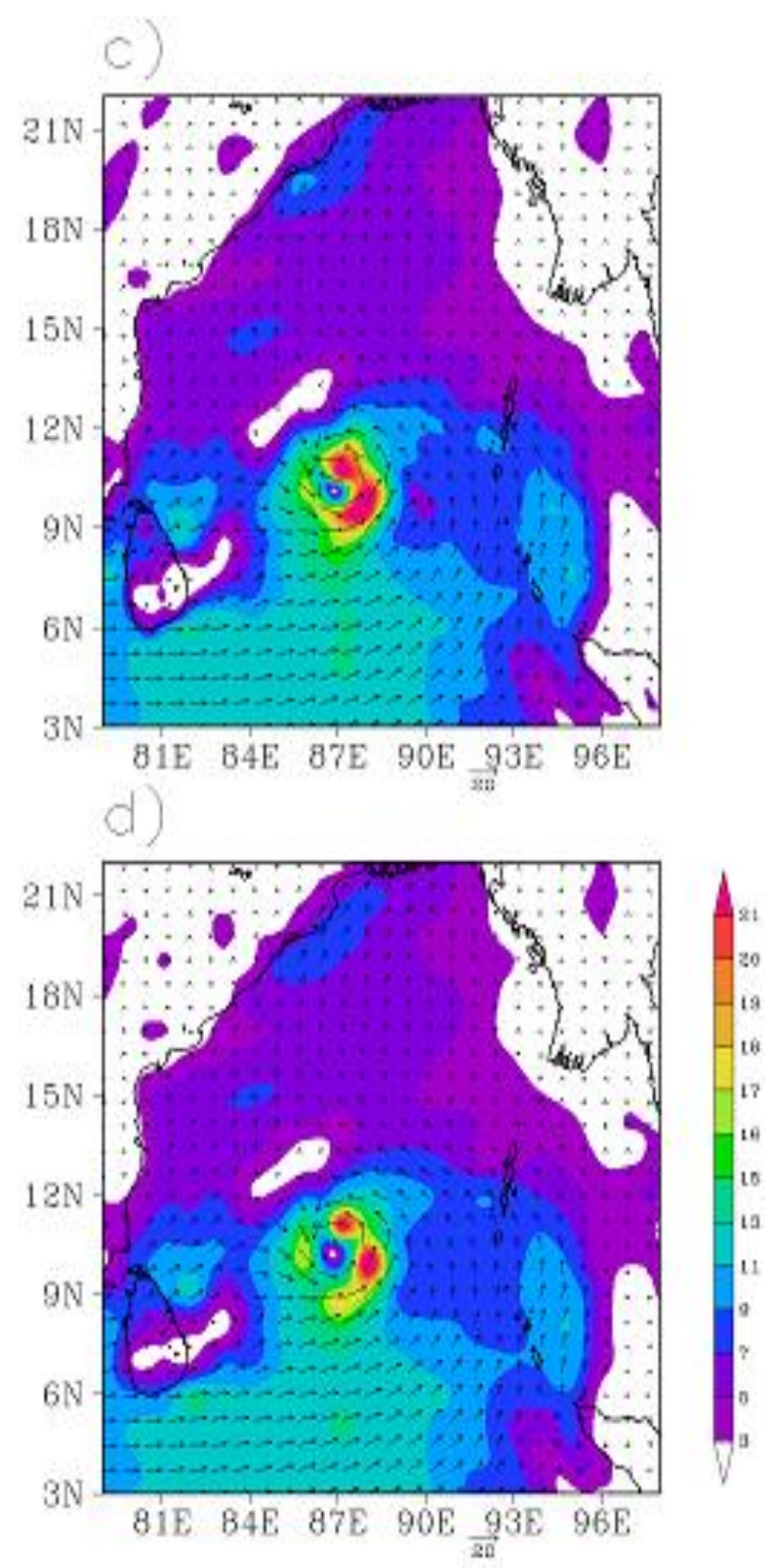

Fig 2: SLP and surface wind at 00:00 UTC 12 May 2013 (a) \& (c) from GFS forecast and (b) \& (d) from FNL forecast 


\section{NUMERICAL EXPERIMENTS AND DATA USED}

Two forecasts of the storm are generated for the period of 120 hours. Both the experiments are initialized at 00:00 UTC of 12 May 2013. For the first and second forecast the initial condition of the model is derived from GFS and FNL analysis respectively and hereafter referred as GFS forecast and FNL forecast. In both forecasts the lateral boundary condition is updated every 3 hourly using NCEP GFS forecasts. The topography for the outer and inner domain is derived from the USGS topography dataset at 10' and '5' resolutions respectively. The model forecasts are validated with the bestfit track dataset obtained from India Meteorological Department (IMD). The Tropical Rainfall Measuring Mission (TRMM) dataset is used to validate the precipitation forecast from the model.

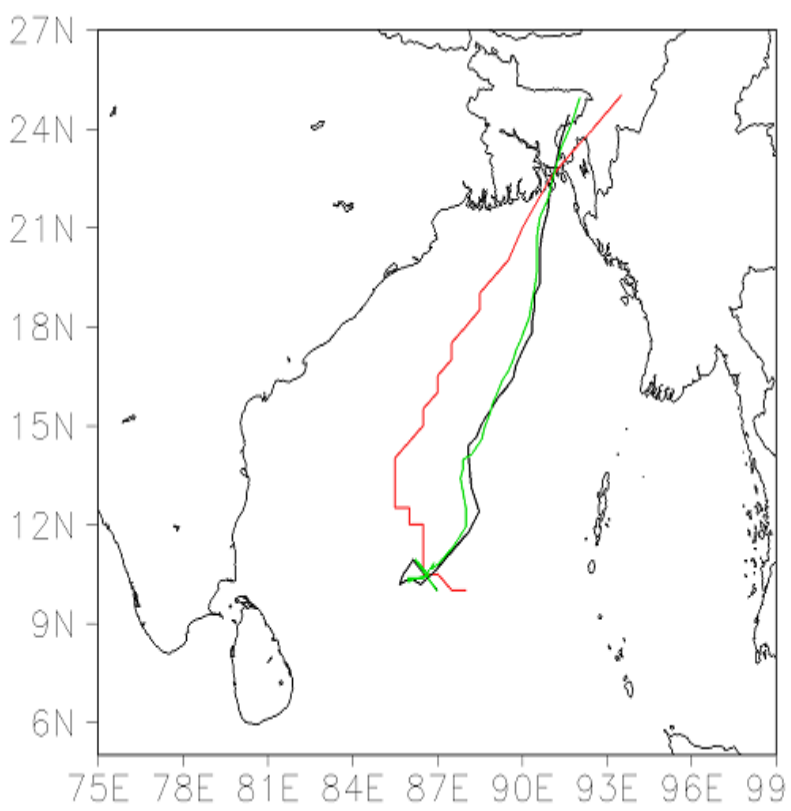

Fig 3: Tracks of the storm as obtained from model forecasts and IMD best-fit data

\section{RESULTS AND DISCUSSIONS}

The results obtained from the two near real time forecast of the storm 'Viyaru' is presented in this section. The model forecasts are compared with the best-fit track datasets to analyze the impact of initial condition on the forecast. The analysis focuses on predicting the track, intensity and landfall of the storm

Fig 2 shows the sea level pressure and surface wind vector fields at initial time (00:00 UTC of 12 May 2013) derived from GFS analysis and FNL analysis. At this stage, the storm at cyclonic stage with minimum SLP of $994 \mathrm{hPa}$ and maximum surface wind (MSW) of $21 \mathrm{~m} / \mathrm{s}$. Fig 2 clearly indicates that the minimum SLP exactly matches with observation, while MSW is overestimating the intensity of the storm. It is also seen that the positional error in the GFS analysis (around $135 \mathrm{~km}$ ) is more compared to that it in the FNL analysis (around $111 \mathrm{~km}$ ).

It is also seen that there is significant changes in the wind structure and magnitude near the core of the cyclone.
However, in the GFS initial condition stronger horizontal wind is observed in the right side of the vortex compared to that in the FNL initial condition.

Fig 3 shows the tracks of the cyclonic storm 'Viyaru' obtained from model forecasts and IMD best-fit track dataset. It is seen that the movement of the storm from 06:00 UTC of 12 May to 18:00 UTC of 13 May in model forecast is towards north-east, whereas the storm was observed to travel northwestward. The direction of movement of the storm from 18:00 UTC of 13 May to 06:00 UTC of 14 May is northerly and well captured by the model in the both forecasts but away from the observation. After that it is seen that the movement of the storm is northeasterly in model forecast and came to close to the observation near landfall which is well captured by the model. In the both predictions the track of the storm is to the right of the observed track up to the landfall after that the forecast track is to the left. However, the track of the storm is better predicted by model in FNL forecast and close to the observation compared to the GFS forecast. Fig 4 represents the vector displacement errors (VDEs) on both the forecasts up to 108 hours at every 12 hour interval. Its clearly indicate that there is a significant improvement in track prediction in FNL forecast. This is due to less initial positional error in FNL forecast. The VDEs at $24 \mathrm{~h}, 48 \mathrm{~h}, 72 \mathrm{~h}$, and $96 \mathrm{~h}$ is about $85,272,287$ and $118 \mathrm{~km}$ respectively in FNL forecast, whereas these errors are 145, 297, 303 and $146 \mathrm{~km}$ respectively in GFS forecast. It is interesting to note that there is statistically significant improvement of $41 \%, 8 \%, 5 \%$ and $19 \%$ in $24 \mathrm{~h}, 48 \mathrm{~h}, 72 \mathrm{~h}$, and $96 \mathrm{~h}$ forecast, in FNL forecast. In both forecasts, the movement of the storm was slower and the storm make landfall 7 hours and 8 hours after the actual landfall at a location $35 \mathrm{~km}$ away to the left of the actual landfall point in FNL and GFS forecast respectively. It is observed that the storm moved at about $40-45 \mathrm{~km} / \mathrm{h}$ on the day of landfall which is not well captured by the model.

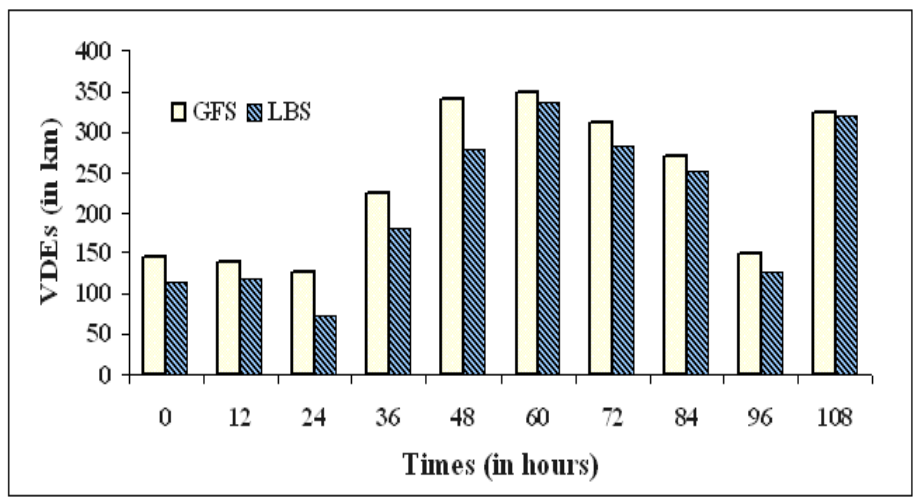

Fig 4: Variation of VDEs (in km) with time (in hours) in model predictions 

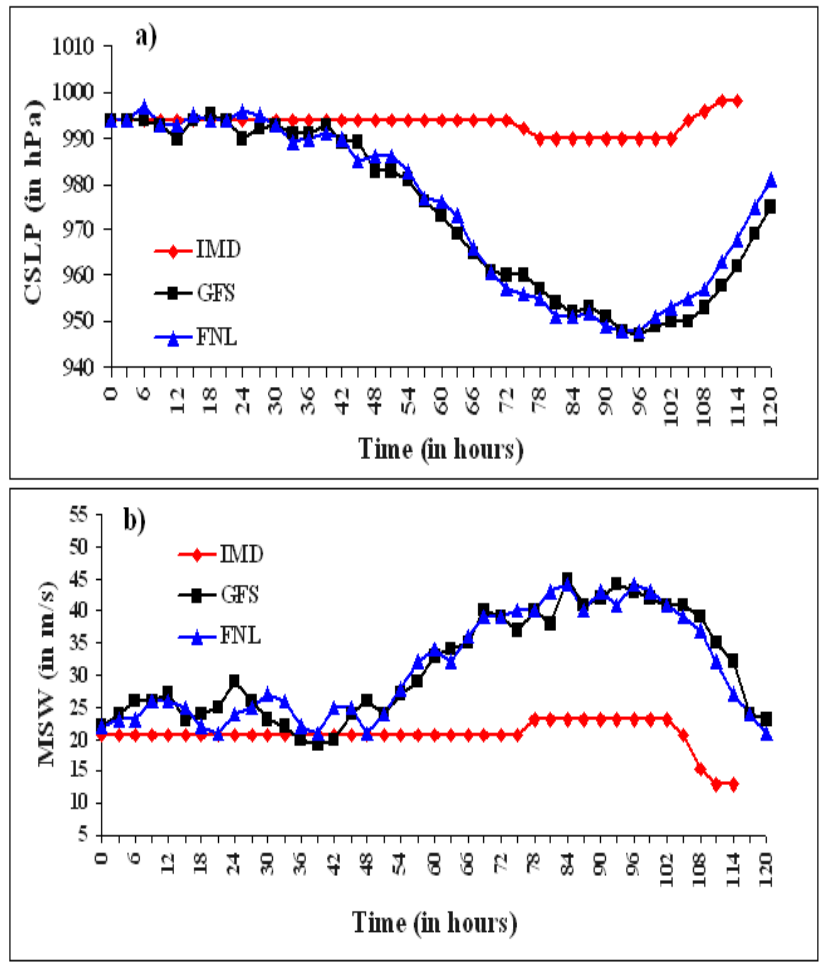

Fig 5: Time evolution in model predicted and observed (a) CSLP (in hPa) (b) MSW (in m/s).

The time evolution of intensity (model predicted and observed) in terms of minimum central sea level pressure (CSLP) and maximum surface wind (MSW) is shown in Fig 5. In the both forecasts the trend of intensification and dissipation of the storm in terms of CSLP and MSW have similar pattern. The intensity of the storm is well captured by the model up to first 45 hours after that the rate of intensification is much sharper in the model forecast. The intensity of the storm in terms of CSLP and MSW is overpredicted in both forecasts. The trend of dissipation is slightly better predicted by the model in FNL forecast. It may be mentioned here that the WRF model is more successful in simulating strong cyclones than weak ones $[29,30]$.

Heavy precipitation associated with tropical cyclone around its landfall causes floods leading to further disaster. Hence it is important here accurate prediction of precipitation, particularly around the landfall time. Fig 6 illustrates the spatial distribution of 24 hours accumulated precipitation around landfall time of the storm (from 0000 UTC of 16 May to 0000 UTC of 17 May) as obtained from model forecast and TRMM observation. Results clearly show that the spatial distribution of accumulated precipitation over land is well predicted by the model in FNL forecast than GFS forecast. The precipitation in the northeastern sector of the storm is better predicted by the model with FNL initial condition. It is mainly due to the fact that the large scale precipitation associated with the storm is better predicted with FNL initial condition. It indicates that the large scale precipitation can be better captured by the model even with courser initial condition.

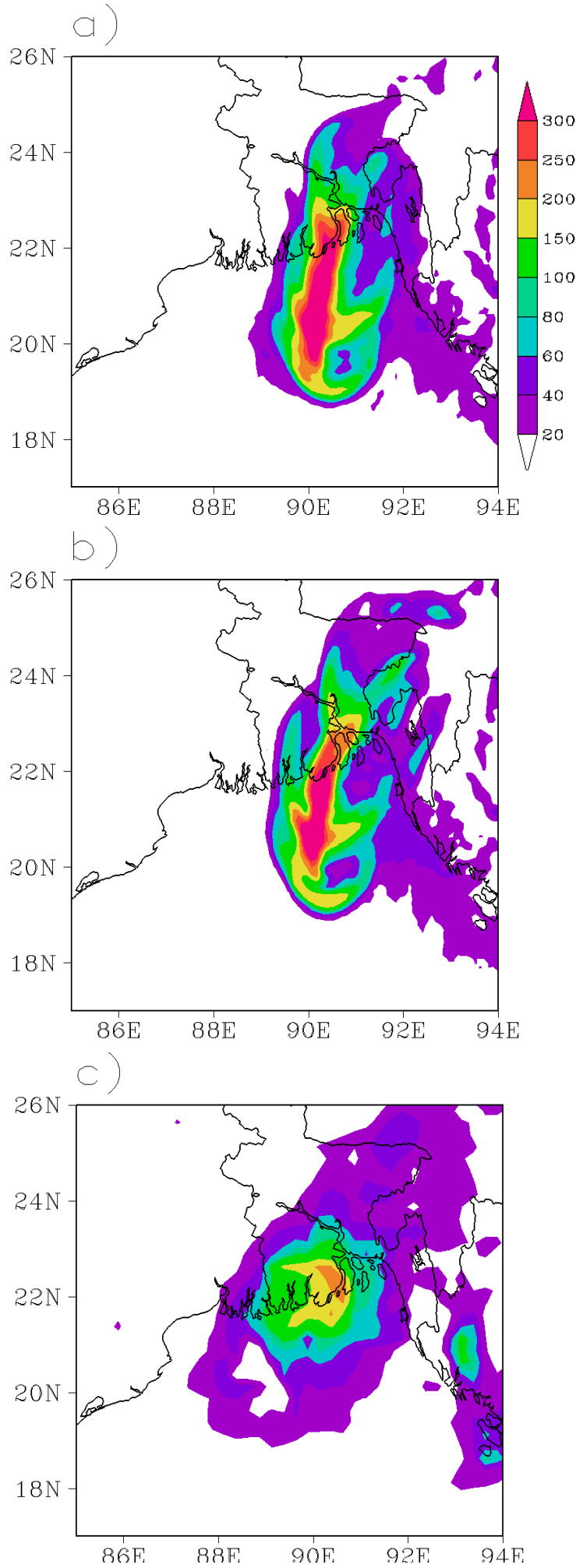

Fig 6: 24h accumulated rainfall valid at 00:00 UTC 17 May from (a) GFS forecast (b) FNL forecast and (c) TRMM 


\section{CONCLUSIONS}

This study evaluates the performance of the WRF-ARW model on mesoscale prediction of Bay of Bengal cyclone 'Viyaru' and investigates the impact of initial condition. In this study the initial condition is derived from NCEP GFS and FNL analysis. The model predicted results are analyzed for the track, landfall, intensity of the storm and associated precipitation. The results presented and discussed in the previous section can be summarized as follow:

The initial positional error is reduced from $134 \mathrm{~km}$ (from GFS analysis) to $111 \mathrm{~km}$ (from FNL analysis) for the prediction of Bay of Bengal cyclone Viyaru. The model initial condition derived from FNL analysis improved the track prediction throughout the forecast period. The VDEs at 24h, 48h, 72h, and $96 \mathrm{~h}$ is about $85,272,287$ and $118 \mathrm{~km}$ respectively in FNL forecast, whereas these errors are 145, 297, 303 and $146 \mathrm{~km}$ respectively in GFS forecast. The result also indicates that the landfall time is better predicted with FNL initial condition. The model predicted track near the landfall of the storm is close to the observation.

The intensity of the storm both in terms of CSLP and MSW is well predicted by the model in first $45 \mathrm{~h}$ forecast and overpredicted in both forecasts. The intensity (both in term of CSLP and MSW) with the trends of dissipation of the storms is better predicted by the model in FNL forecast.

The distribution of precipitation associated with the storm is also better predicted with FNL initial condition. The large scale precipitation associated with the storm is better predicted with FNL initial condition leading to overall better prediction in precipitation distribution.

\section{ACKNOWLEDGMENTS}

The authors sincerely acknowledge Council of Scientific and Industrial Research (CSIR) and Ministry of Earth Science (MoES) for the funding the research activity. We would like acknowledge IMD for providing the best-fit track data; NCEP for GFS analysis and forecast and FNL analysis datasets. The authors also would like to express their appreciation to the WRF model working groups for their effort to develop a mesoscale community model.

\section{REFERENCES}

[1] Emanuel, K. 2005. Increasing destructiveness of tropical cyclones over the past 30 years. Nature, 436, 636-638 doi: 10.1038/nature 03906 .

[2] Bhaskar Rao, D. V., Naidu, C.V., Srinivasa Rao, B. 2001. Trends and fluctuations of the cyclonic systems over North IndianOcean. Mausam, 52(1. 1-8.

[3] Rogers, R., Aberson, S., Black, M., Black, P., Cione, J., Dodge, J., Gamache, J., Kaplan,J., Powell, M., Dunion, J., Uhlhorn, E., Shay, N., and Surgi, N. 2006. The intensity forecasting experiment: A NOAA multiyear field program for improving tropical cyclone intensity forecasts. Bull. Ame. Mete. Soc., 87, 1523-1537, doi: 10.1175/BAMS-87-11-1523.

[4] Rappaport, E.N., Franklin, J. L. , Avila, L.A., Baig, S. R., Beven, J. L., Blake, E. S., Burr, C. A., Jiing, J. G., Juckins, C. A., RKnabb, R. D. , Landsea, C. W., Mainelli, M., Mayfield, M., McAdie, C. J., Pasch, R. J., C. Sisko, R. J. C., Stewart, S. R., and A. N. Tribble, A. N. 2009. Advances and challenges at the National Hurricane Center. Wea. Forecast., 24, 395-419,
[5] Zhang, F., Weng, Y., Gamache, J. F., and Marks, F. D. 2011. Performance of convection-permitting hurricane initialization and prediction during 2008-2010 with ensemble data assimilation of inner core airborne Doppler radar observations. Geophys. Res. Lett., 38, doi: 10.1029/2011GL048469.

[6] De Maria, M. and Kaplan, J. 1999. An updated statistical hurricane intensity prediction scheme for the Atlantic and eastern North Pacific basins", Weather Forecasting, 14, 326-337.

[7] Braun, S. A., Montgomery, M. T. and Pu, Xu. 2006. High-resolution simulation of hurricane Bonnie (1998). Part I: The organization of eyewall vertical motion. J. Atmos. Sci., 63, 19-42.

[8] Chen, S. S. 2006. Overview of RAINEX modeling of 2005 hurri- canes. Preprints, 27th Conf. on Hurricanes and Tropical Meteorology. Amer. Meteor. Soc., 12A.2.

[9] Krishnamurti, T. N. 2005. The hurricane intensity issue. Mon. Wea. Rev., 133, 1886-1912.

[10] Zhu, T., Zhang D. L., and Weng, F. 2004. Numerical simulation of hurricane Bonnie (1998). Part I: Eyewall evolution and intensity changes. Mon. Wea. Rev., 132, 225-241.

[11] Franklin, J. L., Lord, S. J., and Marks Jr, F. D. 1988. Dropwind-sonde and radar observations of the eye of Hurricane Gloria (1985). Mon. Wea. Rev., 116, 1237 1244.

[12] Kossin, J. P., and Eastin, M. D. 2001. Two distinct regimes in the kinematics and thermodynamic structure of the hurricane eye and eyewall. J. Atmos. Sci., 58, 1079-1090.

[13] Houze, R. A., and Coauthors 2006. The Hurricane Rainband and Intensity Change Experiment: Observations and modeling of Hurricanes Katrina, Ophelia, and Rita. Bull. Amer. Meteor. Soc., 87, 15031521.

[14] Pielke, R. A., Matsui, T., Leoncini, G., Nobis, T., Nair, U., Lu, E., Eastman, J., Kumar, S., Peters, C.L., Tian, Y., and Walko, R. 2006. A new paradigm for parameterizations in numerical weather prediction and other atmospheric models. National Wea. Digest, 30, 93 99.

[15] Mandal, M., Mohanty, U. C. 2006. Impact of satellite derived wind in mesoscale simulation of Orissa super cyclone. Indian Jou. Marine Sci., 35(2) 161-173.

[16] Abhilash, S., Das, S., Kalsi, S.R., Gupta, M. D., Mohankumar, K., George, J. P., Banergee, S. K, Thampi, S. B. and Pradhan D. 2007. Impact of doppler radar wind in simulating the intensity and propagation of rain bands associated with mesoscale convective complexes using MM5-3DVAR system. Pure appl. geophys., 164, 1491-1509. DOI 10.1007/s00024-0070235-2.

[17] Singh, R., Pal, P. K., Kishtawal, C. M., Joshi, P. C. 2008. The impact of variational assimilation of SSM/I and QSCAT satellite observations on the numerical simulation of Indian Ocean Tropical Cyclones. Wea. Forecasting, 23, 460-476. 
[18] Routray, A., Mohanty, U.C., Rizvi, S. R. H, Niyogi, D., Osuri, K. K., Pradhan, D. 2010. Impact of doppler weather radar data on numerical forecast of Indian monsoon depressions. Q. J. R. Meteorol. Soc., DOI:10.1002/qj.678.

[19] Srinivas CV, Yesubabu V, Venkatesan R, and Ramarkrishna SSVS. 2010. Impact of assimilation of conventional and satellite meteorological observations on the numerical simulation of a Bay of Bengal Tropical Cyclone of November 2008 near Tamilnadu using WRF model, Meteorol Atmos Phys, 110, 19-44. DOI 10.1007/s00703-010-0102-z

[20] Singh R, Kishtwal CM, Pal PK, and Joshi PC. 2011. Assimilation of the multisatellite data into the WRF model for track and intensity simulation of the Indian Ocean tropical cyclones, Meteorol. Atmos. Phys., 111, 103-119 DOI 10.1007/s00703-011-0127-y.

[21] Osuri, KK., Mohanty UC, Routray A, and Mahapatra M. 2012) The impact of satellite-derived wind data assimilation on track, intensity and structure of tropical cyclones over the North Indian Ocean, Inter. Jour. Rem. Sensing, 33(5) 1627-1652. http://dx.doi.org/10.1080/01431161.2011.596849.

[22] Govindankutty, M., Chandrasekar, A., and Pradhan D. 2010. Impact of 3DVAR assimilation of Doppler Weather Radar wind data and IMD observation for the prediction of a tropical cyclone, Intern. Jour. Rem. Sensing. 31(24) 6327-6345.

[23] Srinivas C. V., Yesubabu, V., Hariprasad R. B. R. R., and Ramarkrishna S. S. V., Venkatraman, B. 2013. Real time prediction of a severe cyclone Jal over Bay of Bengal using a high-resolution mesoscale model WRFARW. Nat. Hazards, 65, 331-357. DOI 10.1007/s11069012-0364-5.
[24] Pan, H. L. and Wu, W. S. 1995. Implementing a mass flux convective parameterization package for the NMC medium-range forecast model. NMC Office Note 409, 40 pp. [Available from NCEP/EMC, 5200 Auth Rd., Camp Springs, MD 20746].

[25] Hong, S.Y., Noh, Y., and Dudhia, J. 2006. A new vertical diffusion package with an explicit treatment of entrainment processes. Mon. Wea. Rev., 134, 2318-2341.

[26] Lin, Y. L., Farley, R.D., Orville, H. D. 1983. Bulk parameterization of the snow field in a cloud model. J. Climate Appl. Meteorol., 22, 1065-1092.

[27] Mlawer, E. J., Taubman, S. J., Brown, P. D., Iacono, M. J., Clough, S. A. 1997. Radiative transfer for inhomogeneous atmosphere: RRTM, a validated correlated-k model for the long-wave. J. Geophys Res., 102(D14. 16663-16682.

[28] Dudhia, J. 1989. Numerical study of convection observed during the winter monsoon experiment using a mesoscale two-dimensional model. J. Atmos. Sci., 46, 3077-3107.

[29] Ryerson W.R., Rugg, S., Elsberry, R.L., Wegiel, J. 2007. Evaluations of the AFWA weather research forecast model Western North Pacific tropical cyclone predictions. http://ams.confex.com/ams/pdfpapers/108856.pdf.

[30] Osuri K. K., Mohanty, U. C., Routray, A., Makarand, A. K., Mohapatra, M. 2011. Customization of WRF-ARW model with physical parameterization schemes for the simulation of tropical cyclones over North Indian Ocean. Natural Hazards, doi 10.1007/s11069-011-9862-0.

[31] Spector, A. Z. 1989. Achieving application requirements. In Distributed Systems, S. Mullender 